\title{
The effect of $\mathrm{Gd}$ substitution in perovskite lanthanum strontium manganite films for use in resistive switching devices
}

\author{
Hong-Sub LEE, Sun Gyu CHOI, Geun Young YEOM* and Hyung-Ho PARK ${ }^{\dagger}$ \\ Department of Materials Science and Engineering, Yonsei University, Seoul 120-749, Korea \\ *Department of Advanced Materials Science and Engineering and SKKU Advanced Institute of Nanotechnology, \\ Sungkyunkwan University, Suwon, Kyunggi-do 440-746, Republic of Korea
}

\begin{abstract}
$\mathrm{La}_{0.7-x} \mathrm{Gd}_{x} \mathrm{Sr}_{0.3} \mathrm{MnO}_{3}$ (LSGMO: $x=0.1,0.3$, and 0.5) perovskite manganite thin films were formed on a $\mathrm{Pt}(111) / \mathrm{Ti} / \mathrm{SiO}{ }_{2} / \mathrm{Si}(100)$ substrate heated to $500^{\circ} \mathrm{C}$ using a radio frequency magnetron sputter. The effects of substituted $\mathrm{Gd}^{3+}$ on the physical, chemical, and electrical properties of perovskite manganite thin films were systematically investigated. $X$-ray diffraction results showed that the crystallinity of the films was affected by the substitution of $\mathrm{La}^{3+}$ with $\mathrm{Gd}^{3+}$ ions. Raman spectroscopy analysis showed an increase in both the tilt of the $\mathrm{MnO}_{6}$ octahedron and the structural distortion as a result of $\mathrm{Gd}^{3+}$ substitution. This is due to the increased structural instability of LSGMO associated with the rhombohedral structure, which can be contrasted with a stable crystalline structure of $\mathbf{G d}_{0.7} \mathrm{Sr}_{0.3} \mathrm{MnO}_{3}$ such as orthorhombic. From the above analyses, it was revealed that structural distortion, crystallinity, and bond strength could affect on resistive switching property.
\end{abstract}

(2014 The Ceramic Society of Japan. All rights reserved.

Key-words : $\mathrm{La}_{0.7-x} \mathrm{Gd}_{x} \mathrm{Sr}_{0.3} \mathrm{MnO}_{3}, \mathrm{XPS}$, Raman, Resistive switching

[Received February 14, 2014; Accepted June 11, 2014]

\section{Introduction}

Mixed-valence perovskite manganite $\mathrm{La}_{1-x} \mathrm{Sr}_{x} \mathrm{MnO}_{3}$ (LSMO) films have drawn significant interest for use in memory device applications due to their colossal magnetoresistance (CMR) and colossal electroresistance (CER) properties. The CER corresponds to the large-magnitude resistive switching phenomenon of a reversible and hysteretic insulator-metal transition which can be induced by an applied electric field. ${ }^{1), 2)}$ Resistive random access memory (ReRAM) is a non-volatile memory that can change its resistance between two reversible high and low resistance states with applied voltage pulses. ${ }^{3), 4)}$ The resistive switching phenomena can be used for ReRAM with a simple metal-insulatormetal (MIM) structure, which is attracting considerable attention due to its fast operation speed, low power consumption, and the possibility of a crossbar-array structure. Resistive switching behavior has been observed in various transition metal oxides and mixed-valence perovskite manganites, such as $\mathrm{Ln}_{1-x} \mathrm{~A}_{x} \mathrm{MnO}_{3}$, where Ln represents a trivalent lanthanide cation and A represents a divalent alkaline earth cation. Various resistive switching mechanisms have been proposed including the Mott transition, Schottky barrier height effect, Jahn-Teller effect and oxygen vacancy migration effect. ${ }^{5)}$

Perovskite manganite films show bipolar resistive switching behavior in terms of an interface-type resistive switching model. ${ }^{\text {) }}$ In this case of interface-type resistive switching, a resistance change occurs at the interface between the metal electrode and the oxide. Recent studies have demonstrated that the electrochemical migration of oxygen ions and the redox between the reactive top electrode and the manganite film in the vicinity of the interface are a primary cause of interface-type resistive switching. ${ }^{6), 7)}$

Goldschmidt's tolerance factor ( $t$ ) has typically been used as a

Corresponding author: H.-H. Park; E-mail: hhpark@yonsei.ac.kr

* Preface for this article: Dol http://dx.doi.org/10.2109/jcersj2.122.P8-1 basis for the formation of the perovskite structure, and a number of researchers have used this tolerance factor to discuss the stability of the perovskite structure. ${ }^{8)}$ An ideal perovskite structure has an $\mathrm{ABX}_{3}$ stoichiometry with a cubic crystal structure, which is composed of the three-dimensional framework of corner-shared $\mathrm{BX}_{6}$ octahedrons. The A-site cation fills the 12 coordinate cavities formed by the $\mathrm{BX}_{6}$ network and is surrounded by 12 equidistant $\mathrm{X}$ anions. ${ }^{9)}$ The electrical and magnetic properties of $\mathrm{La}_{1-x} \mathrm{Sr}_{x} \mathrm{MnO}_{3}$ perovskite manganite are affected by the lattice deformation that results from a change in the $\mathrm{Mn}-$ $\mathrm{O}-\mathrm{Mn}$ bond angle, dependent upon the cation size. As the radius of the A site cation $\left(\mathrm{La}_{1-x} \mathrm{Sr}_{x}\right)$ decreases, the lattice structure transforms from rhombohedral to orthorhombic. This lattice transformation affects the electrical conductivity of the perovskite manganite, and the conductivity can be explained via terms of a band width (or transfer integral) and an electron correlation (on-site Coulomb repulsion). ${ }^{10)}$

In this study, the tolerance factor of $\mathrm{La}_{0.7} \mathrm{Sr}_{0.3} \mathrm{MnO}_{3}$ films was varied via the substitution of $\mathrm{La}^{3+}$ with $\mathrm{Gd}^{3+}$ to induce an $\mathrm{MnO}_{6}$ octahedral distortion. The effects of structural distortion, crystallinity, and bond strength on the resistive switching property of perovskite manganite film were demonstrated.

\section{Experimental procedures}

$\mathrm{La}_{0.7-x} \mathrm{Gd}_{x} \mathrm{Sr}_{0.3} \mathrm{MnO}_{3}$ (LGSMO, $x=0.1,0.3$ and 0.5 ) perovskite manganite films were prepared on $\mathrm{Pt}(111) / \mathrm{Ti} / \mathrm{SiO}_{2} / \mathrm{Si}(100)$ substrates via RF magnetron sputtering from a powder target. The LGSMO targets were prepared via the standard solid-state reaction method using $\mathrm{La}_{2} \mathrm{O}_{3}, \mathrm{Gd}_{2} \mathrm{O}_{3}, \mathrm{SrCO}_{3}$, and $\mathrm{Mn}_{2} \mathrm{O}_{3}$ powders as starting materials. The working pressure was 5 mTorr, the substrate temperature was maintained at $500^{\circ} \mathrm{C}$, and the $\mathrm{Ar}$ gas flow rate was $20 \mathrm{sccm}$ during film deposition. The thickness of the manganite films was approximately $250 \mathrm{~nm}$. The Au $(50 \mathrm{~nm}) / \mathrm{Al}(150 \mathrm{~nm})$ top electrode film was patterned on the films via e-beam evaporator using a metal shadow mask $200 \mu \mathrm{m}$ 
in diameter.

The crystal structure of the films was analyzed via glancingangle X-ray diffraction (GAXRD), using a Rigaku diffractometer with $\mathrm{Cu} K \alpha$ radiation of $1.5418 \AA$, and an incident angle of $1^{\circ}$. The surface morphology was studied via atomic-force microscopy (AFM) using an XE-100 (Park systems) in non-contact mode. Raman measurements were conducted with a LabRam HR using the $514.532 \mathrm{~nm}$ line of an Ar laser for excitation. The chemical bonding states in the films were analyzed via X-ray photoelectron spectroscopy (XPS), using a K-alpha (Thermo VG) with a monochromated $\mathrm{Al} \mathrm{K} \alpha$ radiation source $(\mathrm{h} \nu=1486.6 \mathrm{eV})$ and $50 \mathrm{eV}$ of pass energy. The sampling area was $400 \mu \mathrm{m}$ in diameter, and depth was approximately $3 \mathrm{~nm}$. Current-voltage (I-V) characteristics were measured using an Agilent B1500A semiconductor device analyzer. A positive bias was defined as a flow of current from the top $(\mathrm{Au} / \mathrm{Al})$ to the bottom $(\mathrm{Pt})$ metal electrodes of the MIM structure. Current-voltage characteristics were measured via a voltage bias sweep, as $0 \rightarrow+\mathrm{V}_{\max } \rightarrow 0 \rightarrow$ $-\mathrm{V}_{\max } \rightarrow 0 \mathrm{~V}$. All I-V measurements were taken at room temperature, and a compliance of $10 \mathrm{~mA}$ was applied to prevent breakdown of the MIM structure.

\section{Results and discussion}

The tolerance factors of LGSMO perovskite manganite compounds were calculated using the equation, $\mathrm{t}=\left[\mathrm{r}\left(\mathrm{O}^{2-}\right)+\right.$ $\left.(0.7-x) \mathrm{r}\left(\mathrm{La}^{3+}\right)+x \mathrm{r}\left(\mathrm{Gd}^{3+}\right)+0.3 \mathrm{r}\left(\mathrm{Sr}^{2+}\right)\right] / 2^{1 / 2} \quad\left[\mathrm{r}\left(\mathrm{O}^{2-}\right)+0.7 \mathrm{r}-\right.$ $\left.\left(\mathrm{Mn}^{3+}\right)+0.3 \mathrm{r}\left(\mathrm{Mn}^{4+}\right)\right]$. The ionic radii of $\mathrm{La}^{3+}, \mathrm{Gd}^{3+}$, and $\mathrm{Sr}^{2+}$ were used with 12 coordinated values, while for $\mathrm{Mn}^{3+}$ and $\mathrm{Mn}^{4+}$, 6 coordinated values were used. ${ }^{11)}$ Table 1 shows the calculated $t$ values of the LGSMO films.

Figure 1 shows the GAXRD patterns of $\mathrm{La}_{0.7-x} \mathrm{Gd}_{x} \mathrm{Sr}_{0.3} \mathrm{MnO}_{3}$ $(x=0.1,0.3$, and 0.5$)$ thin films, which have tolerance factors ranging from 0.983 to 0.963 . In Fig. $1, \mathrm{La}_{0.7-x} \mathrm{Gd}_{x} \mathrm{Sr}_{0.3} \mathrm{MnO}_{3}$ $(x=0.1,0.3$ and 0.5$)$ films show polycrystalline and rhombohedral structures. The diffraction peaks were indexed as (012), (110), (104), (024), (122), (214), and (208) for rhombohedral LGSMO, ${ }^{12)}$ and the diffraction intensity weakened with increased Gd substitution. Generally, $\mathrm{La}_{0.7} \mathrm{Sr}_{0.3} \mathrm{MnO}_{3}$ and $\mathrm{Gd}_{0.7} \mathrm{Sr}_{0.3} \mathrm{MnO}_{3}$ (GSMO) are known to have rhombohedral and orthorhombic structures, respectively; ${ }^{13), 14)}$ thus a substitution of $\mathrm{La}^{3+}$ cations with $\mathrm{Gd}^{3+}$ cations in LSMO causes a change in crystal structure from rhombohedral to orthorhombic. Weakened diffraction intensity with increasing Gd substitution may correspond to a reduced crystalline state due to the increased structural instability of rhombohedral LGSMO. This effect can be confirmed using the Scherrer equation to perform a crystallite size estimation. ${ }^{15)}$ The average crystallite sizes of $\mathrm{La}_{0.6} \mathrm{Gd}_{0.1} \mathrm{Sr}_{0.3} \mathrm{MnO}_{3}, \mathrm{La}_{0.4} \mathrm{Gd}_{0.3}-$ $\mathrm{Sr}_{0.3} \mathrm{MnO}_{3}$, and $\mathrm{La}_{0.2} \mathrm{Gd}_{0.5} \mathrm{Sr}_{0.3} \mathrm{MnO}_{3}$ were calculated as 22.4 , 16.6 , and $12.7 \mathrm{~nm}$, respectively. The surface morphologies of the LGSMO films were obtained by using an AFM in noncontact mode, Fig. 2. The root mean square (RMS) roughness of the $\mathrm{La}_{0.6} \mathrm{Gd}_{0.1} \mathrm{Sr}_{0.3} \mathrm{MnO}_{3}, \mathrm{La}_{0.4} \mathrm{Gd}_{0.3} \mathrm{Sr}_{0.3} \mathrm{MnO}_{3}$, and $\mathrm{La}_{0.2} \mathrm{Gd}_{0.5^{-}}$

Table 1. Tolerance factors, and $\mathrm{Mn}^{3+}$ and $\mathrm{Mn}^{4+}$ ions content in $\mathrm{La}_{0.7-x} \mathrm{Gd}_{x} \mathrm{Sr}_{0.3} \mathrm{MnO}_{3}$

\begin{tabular}{cccc}
\hline Thin films & Tolerance factor & $\mathrm{Mn}^{3+}$ content & $\mathrm{Mn}^{4+}$ content \\
\hline $\mathrm{La}_{0.6} \mathrm{Gd}_{0.1} \mathrm{Sr}_{0.3} \mathrm{MnO}_{3}$ & 0.983 & & \\
$\mathrm{La}_{0.4} \mathrm{Gd}_{0.3} \mathrm{Sr}_{0.3} \mathrm{MnO}_{3}$ & 0.973 & 0.7 & 0.3 \\
$\mathrm{La}_{0.2} \mathrm{Gd}_{0.5} \mathrm{Sr}_{0.3} \mathrm{MnO}_{3}$ & 0.963 & & \\
\hline
\end{tabular}

Ionic radii: $12 \mathrm{CN}$ : $\mathrm{La}^{3+}=1.360 \AA, \mathrm{Gd}^{3+}=1.227 \AA, \mathrm{Sr}^{2+}=1.440 \AA$ $6 \mathrm{CN}: \mathrm{Mn}^{3+}=0.645 \AA, \mathrm{Mn}^{4+}=0.530 \AA$ $\mathrm{O}^{2-}=1.340 \AA$
$\mathrm{Sr}_{0.3} \mathrm{MnO}_{3}$ films were $1.283,1.012$, and $0.624 \mathrm{~nm}$, respectively. The decrease in RMS roughness and particle-shape regularity with increasing Gd content is due to the reduced crystallinity of the LGSMO films. The change in surface topography of the films with increasing Gd content, shown in Fig. 1, reflects the reduced crystallinity of the films.

Figure 3(a) shows the Raman spectra of LGSMO films where the three main peaks correspond to the following modes and symmetries: $\mathrm{A}_{\mathrm{g}}(2)$ at $190-245 \mathrm{~cm}^{-1}$ and $\mathrm{A}_{\mathrm{g}}(3)$ at $470-500 \mathrm{~cm}^{-1}$ are rotation and bending modes from the linked $\mathrm{MnO}_{6}$ octa-

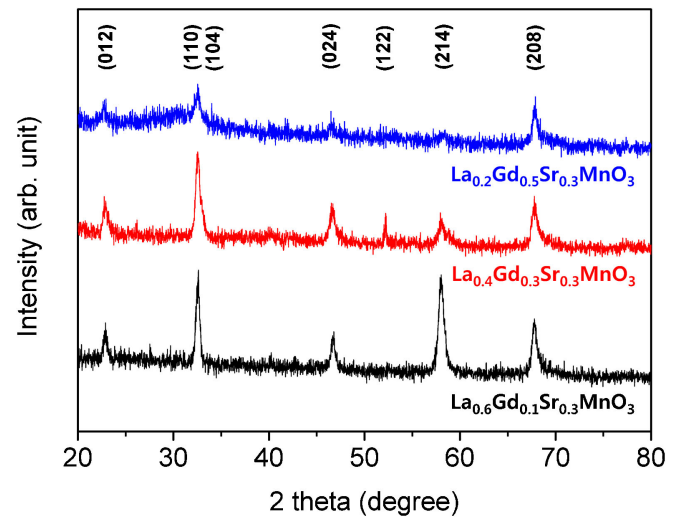

Fig. 1. XRD patterns of $\mathrm{La}_{0.7-x} \mathrm{Gd}_{x} \mathrm{Sr}_{0.3} \mathrm{MnO}_{3}(x=0.1,0.3$ and 0.5$)$ films.
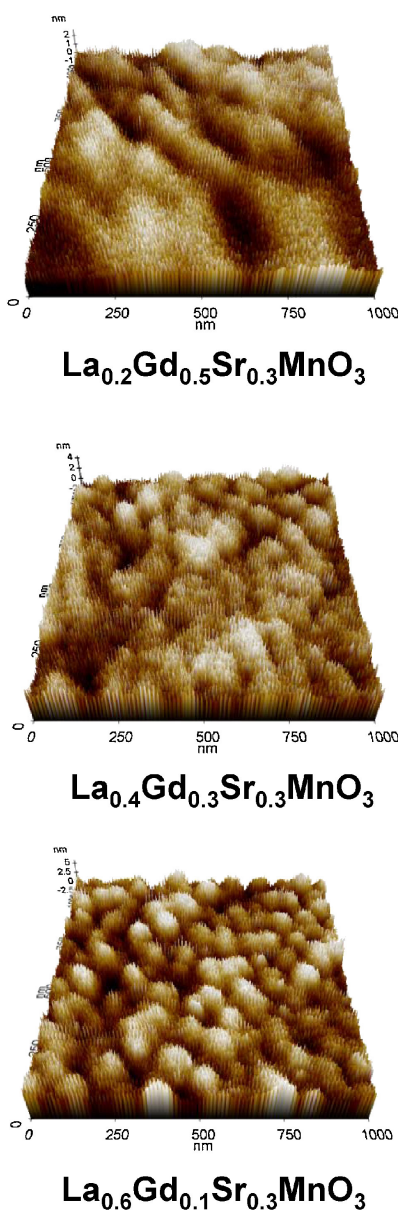

Fig. 2. AFM surface morphologies of $\mathrm{La}_{0.7-x} \mathrm{Gd}_{x} \mathrm{Sr}_{0.3} \mathrm{MnO}_{3}(x=0.1$, 0.3 and 0.5$)$ films. 
(a)

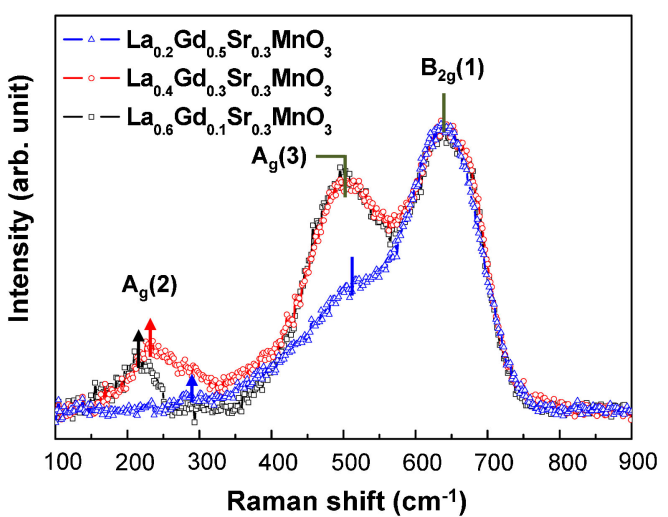

(b)
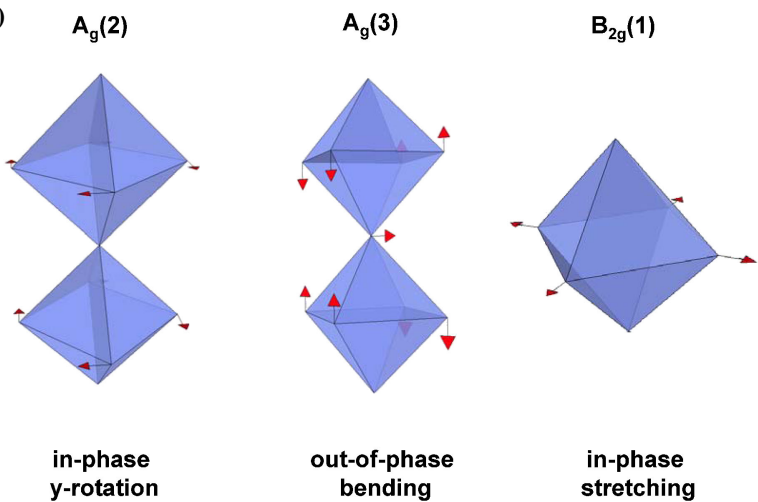

\section{in-phase}

y-rotation bending
$B_{2 g}(1)$

stretching

Fig. 3. (a) Raman spectra of $\mathrm{La}_{0.7-x} \mathrm{Gd}_{x} \mathrm{Sr}_{0.3} \mathrm{MnO}_{3}(x=0.1,0.3$ and $0.5)$ films and (b) each scattering mode scheme: $\mathrm{A}_{\mathrm{g}}(2), \mathrm{A}_{\mathrm{g}}(3)$, and $\mathrm{B}_{2 \mathrm{~g}}(1)$.

hedrons, and $\mathrm{B}_{2 \mathrm{~g}}(1)$ scattering at $610-630 \mathrm{~cm}^{-1}$ is induced by the stretching of the $\mathrm{MnO}_{6}$ octahedron unit. ${ }^{16)-20)}$ The schemes of each scattering mode are represented in Fig. 3(b). As shown in Fig. 3(a), the $A_{g}(2) / A_{g}(3)$ peak positions changed from 216/499 to $232 / 503 \mathrm{~cm}^{-1}$ with increasing Gd contents from 0.1 to 0.3 , respectively. This observed frequency shift was induced by an increased distortion between the $\mathrm{MnO}_{6}$ octahedrons. ${ }^{18)}$ When the Gd substitution amount, $x$, is increased from 0.1 to 0.5 , the average ionic radius of $\mathrm{La}_{0.7-x} \mathrm{Gd}_{x} \mathrm{Sr}_{0.3}$ at the ' $\mathrm{A}$ ' cation site in LGSMO with $\mathrm{ABX}_{3}$ perovskite structure is also decreased from 1.371 to $1.318 \AA$. The decreasing average ionic radius of the ' $A$ ' site cation resulting from increasing $\mathrm{Gd}^{3+}$ substitution affected the y-rotation and bending of the linked $\mathrm{MnO}_{6}$ octahedrons, which is reflected in a shift of the Raman peak a higher wave number. This implies decreased structural stability in the LSGMO with rhombohedral structure; therefore, an absence of an $\mathrm{A}_{\mathrm{g}}(2)$ peak and a significant decrease in the height of the $\mathrm{A}_{\mathrm{g}}(3)$ peak in $\mathrm{La}_{0.2} \mathrm{Gd}_{0.5} \mathrm{Sr}_{0.3} \mathrm{MnO}_{3}$ can be interpreted as a reduced crystalline state with a poor link between $\mathrm{MnO}_{6}$ octahedrons. The $\mathrm{B}_{2 \mathrm{~g}}(1)$ stretching mode at $610-630 \mathrm{~cm}^{-1}$ corresponds to a scattering from the $\mathrm{MnO}_{6}$ octahedron itself, and it is not affected by the crystalline state.

The Mn 2p core-level photoemission spectra of LGSMO films were obtained to monitor a state change in the chemical bond of $\mathrm{Mn}-\mathrm{O}$ in the LSGMO films, resulting from the substitution of $\mathrm{La}^{3+}$ with $\mathrm{Gd}^{3+}$ ions; the results are given in Fig. 4. The $\mathrm{Mn} 2 \mathrm{p}_{3 / 2}$ and $2 p_{1 / 2}$ binding energies were approximately 641.1 and 652.6 $\mathrm{eV}$, respectively. The peak binding energy shift observed with the substitution was insignificant, implying that $\mathrm{Mn}-\mathrm{O}$ bonds in $\mathrm{La}-\mathrm{O}-\mathrm{Mn}$ and $\mathrm{Gd}-\mathrm{O}-\mathrm{Mn}$ show similar ionic/covalent bond characteristic due to the similar electronegativity values of $\mathrm{La}$

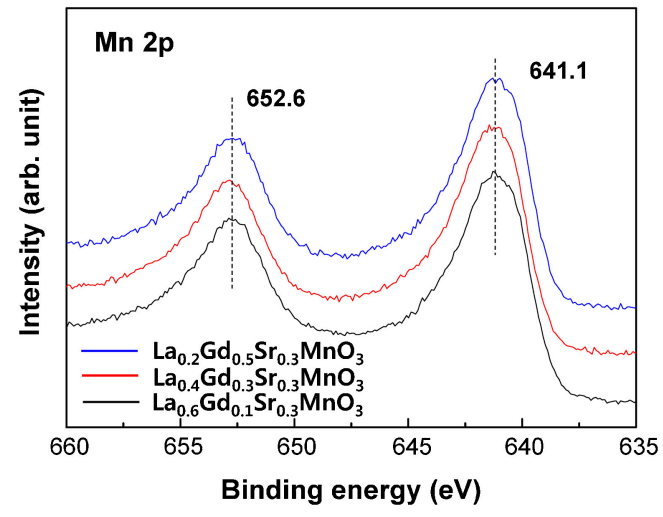

Fig. 4. Mn 2p XPS spectra of $\operatorname{La}_{0.7-x} \mathrm{Gd}_{x} \mathrm{Sr}_{0.3} \mathrm{MnO}_{3}(x=0.1,0.3$ and $0.5)$ films.

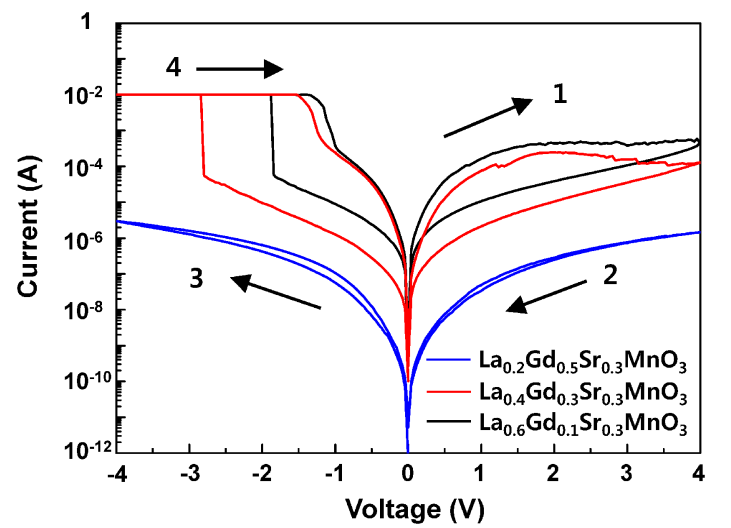

Fig. 5. Resistive switching $\mathrm{I}-\mathrm{V}$ curves of $\mathrm{La}_{0.7-x} \mathrm{Gd}_{x} \mathrm{Sr}_{0.3} \mathrm{MnO}_{3}$ $(x=0.1,0.3$ and 0.5$)$ films.

and Gd. From this result, it can be said that there is almost no change in the chemical bonding state of the LSGMO films, and that the change in chemical bonding state is not a cause of changes in the resistive switching properties of the films with a substitution of $\mathrm{Gd}^{3+}$ for $\mathrm{La}^{3+}$ ions.

Figure 5 shows the $\mathrm{I}-\mathrm{V}$ characteristics of the $\mathrm{Au} / \mathrm{Al} / \mathrm{La}_{0.7-x^{-}}$ $\mathrm{Gd}_{x} \mathrm{Sr}_{0.3} \mathrm{MnO}_{3}(x=0.1,0.3$, and 0.5$) / \mathrm{Pt}$ structures when the maximum positive and negative voltage biases are fixed at $4 \mathrm{~V}$. The figure shows the typical bipolar resistive switching behavior of the interface type with a clockwise direction. ${ }^{6), 7)}$ The applied positive bias voltage changes the resistance state (RS) of LGSMO from a low resistance state (LRS) to a high resistance state (HRS). In the negative bias voltage region, the HRS was switched to LRS which is an initial resistance state. The resistive switching behavior without a forming process is related to the interface-type resistive switching resulting from the electrochemical migration and redox of oxygen ions in perovskite manganite via the applied bias voltage. Upon applying a positive bias voltage to LGSMO films, oxygen ions move to the reactive metal electrode from the LGSMO films, inducing oxidation in the reactive metal top electrode, and an oxygen-deficient layer at the top interfacial region of the LGSMO film, inducing a high resistance state. Conversely, the reverse process is produced in the negative bias voltage, leading to lowered resistivity.6),7),21) The partially-emptied Mn 3d $\mathrm{e}_{\mathrm{g}}^{1} \uparrow$ band of LGSMO contributes an electron conduction via the electron exchange between the $\mathrm{Mn}$ and $\mathrm{O}$ anions. The released electrons from deficient oxygen sites then occupy the partially-emptied Mn $3 \mathrm{~d} \mathrm{e}^{1}{ }_{\mathrm{g}} \uparrow$ band, inducing 
a high insulating state in the LGSMO. ${ }^{7)}$ The resistive switching ratios of the $\mathrm{La}_{0.6} \mathrm{Gd}_{0.1} \mathrm{Sr}_{0.3} \mathrm{MnO}_{3}, \mathrm{La}_{0.4} \mathrm{Gd}_{0.3} \mathrm{Sr}_{0.3} \mathrm{MnO}_{3}$, and $\mathrm{La}_{0.2} \mathrm{Gd}_{0.5} \mathrm{Sr}_{0.3} \mathrm{MnO}_{3}$ films are 41, 169, and 3.1, respectively. The resistive switching ratio was calculated at a reading voltage of $-1 \mathrm{~V}$. As mentioned above, resistive switching is induced via redox between LGSMO and Al electrodes, and the increment of the switching ratio is dependent on the increase in reduction. From this point of view, the low crystalline state of the $\mathrm{La}_{0.2} \mathrm{Gd}_{0.5} \mathrm{Sr}_{0.3} \mathrm{MnO}_{3}$ film reduced the migration rate of oxygen ions and oxidation/reduction amount of oxygen, ${ }^{21)}$ though the $\mathrm{La}_{0.4} \mathrm{Gd}_{0.3} \mathrm{Sr}_{0.3} \mathrm{MnO}_{3}$ film showed a larger resistive switching ratio than $\mathrm{La}_{0.6} \mathrm{Gd}_{0.1} \mathrm{Sr}_{0.3} \mathrm{MnO}_{3}$ film. This data shows that a substitution of $\mathrm{La}^{3+}$ with $\mathrm{Gd}^{3+}$ offers a favorable condition for electrochemical migration and redox due to reduced bond strength. ${ }^{22)}$ For example, the bond dissociation energies of $\mathrm{La}-\mathrm{O}$ and $\mathrm{Gd}-\mathrm{O}$ are 799 and $716 \mathrm{~kJ} / \mathrm{mol}$, respectively. From these structural factors and bond strength changes, the resistive switching properties of LGSMO perovskite manganite films, as a switching ratio, can be changed by the substitution of an A-site cation.

\section{Conclusions}

The tolerance factor of polycrystalline LGSMO films was controlled via Gd substitution. The crystallinity and lattice stability of LGSMO films with rhombohedral structure was degraded with increasing amounts of $\mathrm{Gd}$. The $\mathrm{La}_{0.4} \mathrm{Gd}_{0.3} \mathrm{Sr}_{0.3} \mathrm{MnO}_{3}$ film shows the largest resistive switching curve; this could be linked to a decrease in bond strength providing a favorable condition for electrochemical migration and redox. In addition, high structural disorder in the form of low crystallinity obstructs the resistive switching process. Therefore, the Gd substitution in the $\mathrm{La}_{0.7} \mathrm{Sr}_{0.3} \mathrm{MnO}_{3}$ film affects the redox between the top electrode and manganite film in the resistive switching process, and could change the resistive switching properties.

Acknowledgments This work was supported by the Industrial Strategic technology development program (10041926, Development of high density plasma technologies for thin film deposition of nanoscale semiconductor and flexible display processing) funded by the Ministry of Knowledge Economy (MKE, Korea). This work was supported by the third Stage of Brain Korea 21 Plus Project in 2014. The experiments at the PLS were supported in part by MEST and POSTECH

\section{References}

1) Y. Tokunaga, Y. Kaneko, J. P. He, T. Arima, A. Sawa, T. Fujii, M. Kawasaki and Y. Tokura, Appl. Phys. Lett., 88, 223507 (2006).

2) Z. Trajanovic, C. Kwon, M. C. Robson, K.-C. Kim, M. Rajeswari, R. Ramesh, T. Venkatesan, S. E. Lofland, S. M. Bhagat and D. Fork, Appl. Phys. Lett., 69, 1005-1007 (1996).

3) S.-L. Li, Z. L. Liao, J. Li, J. L. Gang and D. N. Zheng, J. Phys. D: Appl. Phys., 42, 045411 (2009).

4) S. T. Hsu, T. Li and N. Awaya, J. Appl. Phys., 101, 024517 (2007).

5) R. Waser, R. Dittmann, G. Staikov and K. Szot, Adv. Mater., 21, 2632-2663 (2009).

6) A. Sawa, Mater. Today, 11, 28-36 (2008).

7) H. S. Lee, S. G. Choi, M. J. Rozenberg and H. H. Park, Sci. Rep., 3, 1704 (2013).

8) V. M. Goldschmidt, Ber. Dtsch. Chem. Ges., 60, 1263-1296 (1927).

9) C. Li, K. C. K. Soh and P. Wu, J. Alloys Compd., 372, 40-48 (2004).

10) M. B. Salamon and M. Jaime, Rev. Mod. Phys., 73, 583-628 (2001).

11) S. V. Trukhanov, J. Exp. Theor. Phys., 100, 95-105 (2005)

12) J. Feng, S. Qi, X. Hou and M. Zhang, Solid State Sci., 9, 10331035 (2007).

13) A. P. Ramirez, J. Phys.: Condens. Matter, 9, 8187-8199 (1997).

14) J. P. Zhou, J. T. McDevitt, J. S. Zhou, H. Q. Yin, J. B. Goodenough, Y. Gim and Q. X. Jia, Appl. Phys. Lett., 75, 1146-1148 (1999).

15) T. Shozui, K. Tsuru, S. Hayakawa and A. Osaka, J. Ceram. Soc. Japan, 116, 530-535 (2008).

16) M. N. Iliev and M. V. Abrashev, J. Raman Spectrosc., 32, 805811 (2001)

17) V. A. Amelitchev, B. Güttler, O. Y. Gorbenko, A. R. Kaul, A. A. Bosak and A. Y. Ganin, Phys. Rev. B, 63, 104430 (2001).

18) V. Dediu, C. Ferdeghini, F. C. Matacotta, P. Nozar and G. Ruani, Phys. Rev. Lett., 84, 4489-4492 (2000).

19) B. Güttler, V. A. Amelitchev, O. Y. Gorbenko and A. R. Kaul, Phase Transit., 76, 63-72 (2003).

20) M. N. Iliev, M. V. Abrashev, H.-G. Lee, V. N. Popov, Y. Y. Sun, C. Thomsen, R. L. Meng and C. W. Chu, Phys. Rev. B, 57, 2872-2877 (1998).

21) S. Asanuma, H. Akoh, H. Yamada and A. Sawa, Phys. Rev. B, 80, 235113 (2009).

22) A. Kushima and B. Yildiz, J. Mater. Chem., 20, 4809-4819 (2010). 